\title{
Treatment for varicose veins by ambulatory selective varicose vein ablation, under local anesthesia method
}

\author{
Weonkee Jang, MD \\ Su Varicose Vein Clinic, Incheon, Rep. of Korea
}

\begin{abstract}
Chronic venous disease of lower extremities is a common vascular problem. The method for ambulatory selective varicose vein ablation, under local anesthesia (ASVAL) without saphenous vein ablation, is based on a concept opposite to that of the traditionally accepted method. According to the traditional concept, the ascending evolution of a varicose disease starts from the peripheral veins, that is, involving the smallest and superficial veins with the most fragile walls would be dilated first. However, the theory of ascending evolution is not $100 \%$ valid for all venous diseases. For conducting a successful ASVAL, a vein specialist is recommended to deliberately reject the patients who manifest more advanced varicose disease. A number of patients with varicose veins have been classified as manifesting an earlier stage C2 disease, and they can be treated by performing extensive phlebectomies using ASVAL procedure. If advanced skin changes or ulceration ( $\mathrm{C} 4$ to $\mathrm{C} 6$ disease) have already occurred resulting from the underlying venous disease, any attempt to use the ASVAL method will result in high rates of recurrence, since the saphenous vein and its valves might have already been damaged irreversibly. The criteria for obtaining best results from using ASVAL include: involvement of small saphenous vein, preferably less than $6 \mathrm{~mm}$ in diameter; younger patients, who may respond better; and nulliparous women.
\end{abstract}

Keywords: ASVAL; chronic venous disease; phlebectomy

\section{Introduction}

Approximately one-third of men and women aging between 18 to 64 years are suffering from varicose veins currently [1]. The high prevalence leads to significant health care expenditure on the treatments of varicose veins [2]. The traditional physiopathological concept of primary varicose disease is based on a hypothesis of retrograde hemodynamic evolution of superficial venous insufficiency (SVI), that describes a development of the reflux from connections between the deep venous system and the superficial venous system, especially in the region of confluence with the saphenous veins (SVs). Based on this theory, the occurrence of a reflux in the region of the terminal valve of the SV forms the key point in the evolution, whereby the reflux extends gradually in a retrograde fashion or descends along the SVs, eventually reaching the superficial collateral veins where the varices develop. This description was disseminated for the first time in 1890 by Trendelenburg [3] and was supported much later by Ludbrook and Beale [4] in a more accurate way. In the past decade, a number of publications criticizing the descending theory have evolved, citing the existence of local or multifocal early distal evolution, sometimes ascending or anterograde, in relation to precise as well as detailed EchoDoppler explorations [5,6].

This physiopathological theory contained two consequences. First, before the emergence of saphenous reflux, early treatment 
of varicose veins might be significantly effective in preventing its spread into the SVs. Second, the existence of saphenous reflux to a certain stage prompted for first line therapy, which included ablation of varicose reservoirs (VR) without ablation or stripping of the SV with potentially reversible reflux [7].

\section{Population}

In 2011, the American guidelines relating to varicose diseases were introduced with a grade of recommendation/level of evidence $2 \mathrm{C}$ mentioning that, although promising results are obtained in a group of patients with largely cosmetic concerns, the ambulatory selective varicose vein ablation, under local anesthesia (ASVAL) method should not be generalized, and it is necessary to perform various comparative studies against wellvalidated surgical techniques [8]. The European guidelines published in 2015 also recommended to grade the performance of ASVAL with a class/level of evidence $2 \mathrm{~B}$, stating that in patients with less evolved varicose veins (C2-C3), single phlebectomies with the preservation of saphenous trunk should be considered [9]. The ASVAL procedure yields best results in patients with a limited alteration of the SVs as assessed by the ultrasoundduplex imaging (Minimal dilatation of the SV, presence of a segmental truncal reflux, and presence of a voluminous/unique varicose tributary ideally at the thigh) and with mild chronic venous disease (Asymptomatic, with cosmetic concern, noncomplicated C2), especially in young patients and in nulliparous women (Table 1). The patients not suitable for ASVAL are those with a severe chronic venous insufficiency (C4-C6) with extended damages to the SV (longer saphenous vein with a large diameter, focal dilatations, history of SV thrombosis) or with absence of a large VR [10].

\section{ASVAL procedures}

In the ASVAL procedure, the limbs are treated with ablation

Table 1. CEAP classification

\begin{tabular}{|c|c|c|}
\hline \multirow{2}{*}{$\frac{\text { C-clinical class }}{0}$} & \multicolumn{2}{|c|}{ Characteristic $^{\text {a) }}$} \\
\hline & No clinical findings or symptoms & E etiology ${ }^{\text {b) }}$ \\
\hline 1 & Telangiectasia or reticular veins & C congenital \\
\hline 2 & Varicose veins & S secondary \\
\hline 3 & Edema, only due to a venous etiology & P primary \\
\hline \multirow[t]{2}{*}{4} & (a) Pigmentation and/or eczema & A anatomy ${ }^{b)}$ \\
\hline & (b) Lipodermatosclerosis, atrophie blanche & $\begin{array}{l}\text { S superficial (great and short saphenous systems as well as any } \\
\text { branch varices) }\end{array}$ \\
\hline 5 & Prior uleration, dermatitis & $\begin{array}{l}\text { P perforator (veins that communicate between the superficial } \\
\text { and deep systems) }\end{array}$ \\
\hline 6 & Active ulceration & $\begin{array}{l}\text { D deep (calf veins and sinuses, popliteal, femoral, iliac veins } \\
\text { and vena cava) }\end{array}$ \\
\hline A, S & Subscript asymptomatic, symptomatic & P pathophysiology ${ }^{\text {b) }}$ \\
\hline Date & Date of investigation & $\mathrm{R}$ reflux \\
\hline \multirow[t]{3}{*}{ Level } & Level of investigation (I, II, III) & O obstruction \\
\hline & & R-O both \\
\hline & & $\mathrm{N}^{\mathrm{b})}$ no evident disease $\mathrm{e}^{\mathrm{b})}$ \\
\hline
\end{tabular}

CEAP, clinical, etiologic, anatomic, and pathophysiologic.

${ }^{a)}$ Complaints are expected to be related to venous insufficiency and are not classified if another etiology is present (i.e., edema secondary to heart [failure]), ${ }^{\text {b) }}$ the $\mathrm{N}$ subscript indicates no evidence of disease. It is applicable to E, A, and/or P of CEAP.

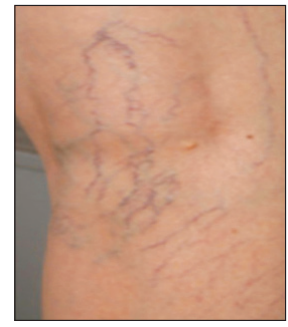

Class 1: Telangiectasia.

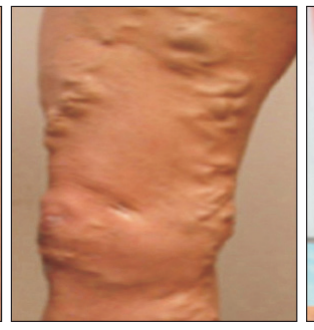

Class 2: Varicose vein.

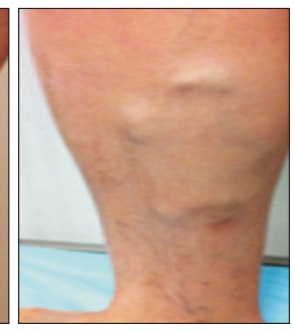

Class 3: Edema.

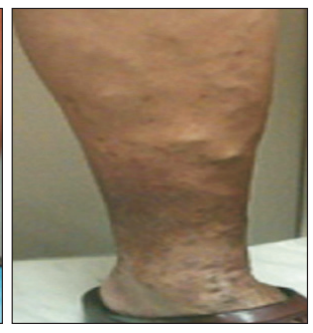

Class 4: Pigmentation/eczema.

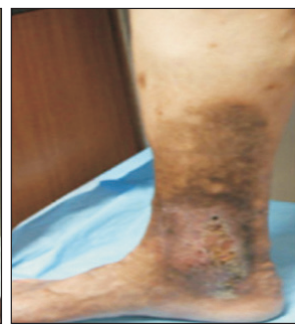

Class 5: Healed ulcer.

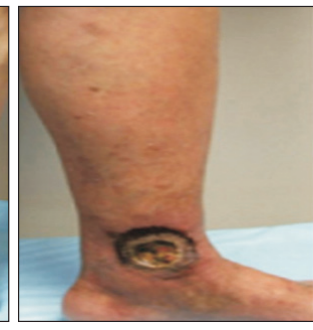

Class 6:

Venous ulcer. 
by performing phlebectomy of the dilated incompetent tributaries of the great saphenous vein (GSV) after locating them preoperatively by ultrasound mapping, and at the same time conserving the refluxing GSV $[11,12]$. The main objective of the ASVAL method is to improve the hemodynamics of the GSV by ablation of dilated and refluxing tributaries of the GSV, resulting into the disappearance of saphenous reflux or at least achieving a significant reduction in the duration of reflux, as reported previously [11-13]. This strategy of treatment is based on the multifocal or ascending evolution theory of the SVI, which explains the beginning of the varicose disease in the superficial network of veins and not in the saphenous vein [14-20]. The marking on the skin before the surgery is mandatory to perform a thorough ablation of the VR. It is essential to conduct the ASVAL procedure under tumescent local anesthesia, because it is more efficient in anesthetizing the part effectively and dramatically reduces bleeding by high subcutaneous pressure due to the accumulation of liquid in large amount. It also enables the surgeon to have a comfortable access for removing the varicose veins. It has been reported that the use of isotonic bicarbonate solution further improves the efficiency of the lidocaine and reduces the amount of lidocaine necessary for tumescence, thereby enabling the surgeon to treat large surfaces on the lower limb [21]. The varicose veins are removed by micro-phlebectomy (Fig. 1). The incisions are made with an 18-gauge needle. The bevel of the needle makes a flap on the skin which facilitates the penetration of the hook through the skin and gives an excellent cosmetic result. The smaller the hook, the better the cosmetic result will be. The phlebectomy may become atraumatic with a precise skin marking which helps to make a micro-incision in front of the vein, thus preventing from scratching the subcutaneous tissues to access the veins. It has been recommended to avoid leaving any remnants of varicose veins in order to get the best cosmetic result, since it limits the risk of pigmented scarring or discoloration [10]. The use magnification glass is mandatory to perform the micro-phlebectomy efficiently. The use of stitches is not necessary owing to the limited size of the micro-incisions performed with the 18-gauge needle. The use of stretch strips has been recommended in order to avoid blisters. Walking is advised immediately after the procedure, and the patient can be discharged from the hospital/clinic in one hour after the mobilization. It is not necessary to wear a stocking postoperatively owing to the minimally invasive nature of the surgery [22].

\section{Discussion}

A long time after the description of the technique of phlebectomy by Muller [23], Pittaluga et al. [7] showed that isolated phlebectomies have a significant effect on the characteristics of reflux in the GSV with a reduction in reflux duration (RD) and peak reflux velocity in a short term. The disappearance of
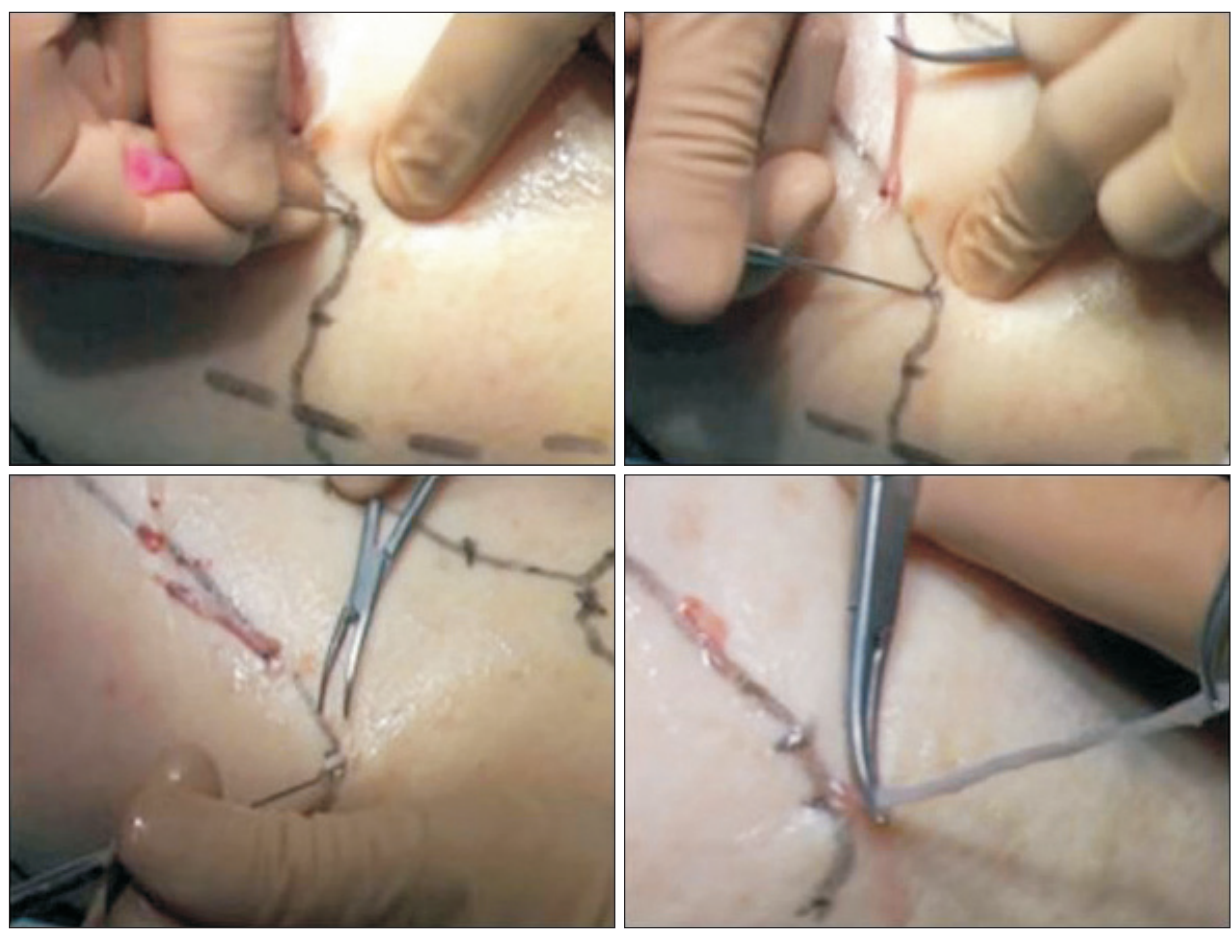

Fig. 1. Technique of micro-phlebectomy performed with 18 gauge needle under tumescent local anesthesia. 
significant reflux from the GSV following phlebectomy or after ablation of an incompetent tributary has been reported in various studies [11-13,24,25]. The reduction of the GSV diameters after ablation of a refluxing collateral has also been reported $[12,26]$. It was quite interesting to note that, in some cases even when reflux persisted beyond 0.5 seconds, there was still a significant reduction in both the velocity and duration of the reflux, and also that in the diameter of the GSV after ablation of the VR by means of a phlebectomy. Pittaluga et al. [7] showed that no significant difference was reported in relation to symptom improvement, even if the saphenous reflux remained after phlebectomy. Therefore, considering the threshold value of 0.5 seconds in defining a reflux as pathological might be questionable [27], since duration is just one characteristic of reflux. Some other studies have shown the relationship between the presence of terminal valve reflux and a wider diameter of the GSV at the junction and the increasing age [19,20,28]. Colignon and Hébrant [29] has reported through another prospective study that, there is a correlation between the GSV reflux volume and the clincal etiologic anatomic and pathophysiologic clinical stage. Other publications [30-32] have also reported about the correlation between phlethysmographic criteria and a clinical or hemodynamic improvement as assessed by Doppler ultrasound, showing the importance of reflux volume in the development of venous insufficiency. The phlebectomies probably reduce the reflux volume explaining the extents of clinical and hemodynamic improvements, irrespective of the fact that RD remains above 0.5 seconds. Pittaluga et al. [11] reported that the hemodynamic and clinical improvement after phlebectomy as well as conservation of a refluxing SV are correlated with the size of the VR treated [12], and thus, correlated with eliminating the refluxing volume. The larger the size of the treated VR, the more pronounced clinical and hemodynamic modifications will result. Furthermore, he reported in the same study [12] that, the recurrences observed during the 4 years of followup after phlebectomies were accompanied by the absence of saphenous reflux in 17 out of the 24 cases. This suggested that there had been an evolution of the varicose recurrence from the superficial venous network which were unrelated to that of the persistent or recurrent SV reflux. Besides, most of the recurrent varices appeared after the endovenous ablation of the GSV despite the obliteration of the saphenous vein $[33,34]$.

The ascending or multifocal physiopathological theory, which challenges the descending evolution along the saphenous axis according to primary valvular insufficiency, is based on several observations. To start with, the rate of varicose recur- rences after surgical or endovenous ablation of the saphenous vein was reported as follows: (1) From 25\% after 5 years according to Kostas et al. [35], to $62 \%$ after 11 years according to Winterborn et al. [36], despite efficiently performed stripping; and (2) From $22.8 \%$ at 3 years according to Labropoulos et al. [37], to $27.4 \%$ after 5 years according to Merchant et al. [33] after endovenous radiofrequency ablation (RFA) treatment, despite the obliteration of the SV in more than $83 \%$ of cases. Perrin et al. [38] also reported that, in $63.7 \%$ of cases, more than one source of reflux was involved during the post-stripping recurrence; and in $45 \%$ of cases, the recurrence involved the saphenous confluence. Also, the disappearance of ostial reflux was reported after endovenous treatment without crossectomy in $93.4 \%$ of cases, according to Min et al. [39]; after endovenous laser ablation treatment in $95.7 \%$ of cases, according to Proebstle et al. [40]; and after RFA in $\mathbf{8 8 . 2 \%}$ of cases, according to Merchant et al. [33]; or in $90.9 \%$ of the latter cases, according to Pichot et al. [41]. Another observation was the reduction in saphenous reflux, which no longer remained significant ( 0.5 seconds) after the phlebectomies in more than two-thirds of the limbs. This finding might be the result of the reduction in the size of the saphenous vein, which was significant in the region of the saphenous confluence, thereby making it possible to detect whether the areas were leak proof. Lurie [42] suggested the possibility of functional insufficiency of the saphenous valves in the absence of any anatomic lesions. According to him, closing of the valves would be caused by the existing pressure in the valvular sinus, in which the pressure would increase in direct proportion to the velocity of the anterograde flow. If this velocity failed to reach a critical value that might allow to attain the pressure that is sufficient to close the valve, the valve would not close. This is the reason as to why a reflux may be present which is able to flow through healthy valves when a patient is in the decubitus position, since the velocity of the anterograde flow is slight. Because ablation of the VR enables to improve the saphenous hemodynamics, it may also enable to eliminate a functional valvular insufficiency by increasing the anterograde velocity. Various biochemical and anatomopathological studies have suggested a parietal hypothesis for explaining evolution of varicose disease, instead of valvular hypothesis [43-45]. Based on this hypothesis, valvular insufficiency occurs as a result of the dilatation of the vein. Besides, anatomoclinical studies have reported that, the presence of varices not only involves the saphenous confluence as observed in $50 \%$ of cases [16,46], but also involves the SV often either partially or wholly $[18,20]$.

There is no treatment that can characterize itself as being 
"radical" with regard to the treatment of varices, probably because the natural history of varicose disease differs from patient to patient, thereby questioning concept of the traditional descending physiopathological theory. Consequently, regardless of the treatment technique, it is logical to contemplate a longterm follow-up for the patients treated for varices by adapting the procedures and selecting the techniques on a case-by-case basis, and by abandoning invariable and needlessly destructive treatments $[47,48]$. The choice of a treatment limited to phlebectomy may be the first-line treatment in varicose diseases in spite of the evolved stages, because it happens to be minimally invasive procedure, it focuses on the VR as well as preserves the saphenous axis which is essential in the recuperative process. Preservation of the SV, whose physiological role may have been neglected perhaps, should be considered as a significant factor for the long-term management of varicose disease.

\section{Conclusion}

The ASVAL technique opposes the usual approach to treat the SV systematically by stripping, or by endothermal or chemical ablation in presence of varicose veins with a SV reflux. It is opposite to a modern concept of an individualized treatment, since every patient has a different clinical and hemodynamic situation of the disease at time of treatment. This may not match with the traditional treatment strategy accepted in general for all patients with varicose diseases. The ASVAL treatment focused on the fact that, VR can improve the clinical and hemodynamic conditions, preserve the venous drainage, and prevent a predictable deterioration in a large group of selected patients. In addition, the treatment of varicose veins with a microsurgical technique has also provided good cosmetic benefits [10].

\section{Conflicts of interest}

The author has nothing to disclose.

\section{References}

1. Evans CJ, Fowkes FG, Ruckley CV, Lee AJ. Prevalence of varicose veins and chronic venous insufficiency in men and women in the general population: Edinburgh Vein Study. J Epidemiol Community Health 1999;53:149-53.

2. Beale RJ, Gough MJ. Treatment options for primary varicose veins--a review. Eur J Vasc Endovasc Surg 2005;30:83-95.

3. Trendelenburg F. Ueber die unterbindung der vena sa- phena magna bei Unterschenkelvaricen. Beitr Z Klin Chir 1890;7:195-210.

4. Ludbrook J, Beale G. Femoral venous valves in relation to varicose veins. Lancet 1962;1:79-81.

5. Labropoulos N, Kokkosis AA, Spentzouris G, Gasparis AP, Tassiopoulos AK. The distribution and significance of varicosities in the saphenous trunks. J Vasc Surg 2010;51:96-103.

6. Chastanet S, Pittaluga P. Influence of the competence of the sapheno-femoral junction on the mode of treatment of varicose veins by surgery. Phlebology 2014;29(1 Suppl):61-5.

7. Pittaluga P, Chastanet S, Locret T, Barbe R. The effect of isolated phlebectomy on reflux and diameter of the great saphenous vein: a prospective study. Eur J Vasc Endovasc Surg 2010;40:122-8.

8. Gloviczki P, Comerota AJ, Dalsing MC, Eklof BG, Gillespie DL, Gloviczki ML, et al. The care of patients with varicose veins and associated chronic venous diseases: clinical practice guidelines of the Society for Vascular Surgery and the American Venous Forum. J Vasc Surg 2011;53(5 Suppl):2S-48S.

9. Wittens C, Davies AH, Bækgaard N, Broholm R, Cavezzi A, Chastanet S, et al. Editor's choice - management of chronic venous disease: clinical practice guidelines of the European Society for Vascular Surgery (ESVS). Eur J Vasc Endovasc Surg 2015;49:678-737.

10. Pittaluga $P$, Chastanet S. The ASVAL story. Vein Mag 2017;10.

11. Pittaluga P, Rea B, Barbe R. Méthode ASVAL (Ablation Sélective des Varices sous Anesthésie Locale): principes et résultatspréliminaires. J Mal Vascul 2005;30:44.

12. Pittaluga P, Chastanet S, Rea B, Barbe R. Midterm results of the surgical treatment of varices by phlebectomy with conservation of a refluxing saphenous vein. J Vasc Surg 2009;50:10718.

13. Zamboni P, Cisno C, Marchetti F, Quaglio D, Mazza P, Liboni A. Reflux elimination without any ablation or disconnection of the saphenous vein. A haemodynamic model for venous surgery. Eur J Vasc Endovasc Surg 2001;21:361-9.

14. Labropoulos N, Giannoukas AD, Delis K, Mansour MA, Kang SS, Nicolaides AN, et al. Where does venous reflux start? J Vasc Surg 1997;26:736-42.

15. Labropoulos N, Kang SS, Mansour MA, Giannoukas AD, Buckman J, Baker WH. Primary superficial vein reflux with competent saphenous trunk. Eur J Vasc Endovasc Surg 1999;18:201-6.

16. Cooper DG, Hillman-Cooper CS, Barker SG, Hollingsworth SJ. Primary varicose veins: the sapheno-femoral junction, distribution of varicosities and patterns of incompetence. Eur 
J Vasc Endovasc Surg 2003;25:53-9.

17. Labropoulos N, Leon L, Kwon S, Tassiopoulos A, GonzalezFajardo JA, Kang SS, et al. Study of the venous reflux progression. J Vasc Surg 2005;41:291-5.

18. Engelhorn CA, Engelhorn AL, Cassou MF, Salles-Cunha SX. Patterns of saphenous reflux in women with primary varicose veins. J Vasc Surg 2005;41:645-51.

19. Caggiati A, Rosi C, Heyn R, Franceschini M, Acconcia MC. Age-related variations of varicose veins anatomy. J Vasc Surg 2006;44:1291-5.

20. Pittaluga P, Chastane S, Rea B, Barbe R. Classification of saphenous refluxes: implications for treatment. Phlebology 2008;23:2-9.

21. Creton D, Réa B, Pittaluga P, Chastanet S, Allaert FA. Evaluation of the pain in varicose vein surgery under tumescent local anaesthesia using sodium bicarbonate as excipient without any intravenous sedation. Phlebology 2012;27:368-73.

22. Pittaluga $\mathrm{P}$, Chastanet $\mathrm{S}$. Value of postoperative compression after mini-invasive surgical treatment of varicose veins. J Vasc Surg Venous Lymphat Disord 2013;1:385-91.

23. Muller R. Traitement des varices par phlébectomie ambulatoire. Phlébologle 1966;19:277-9.

24. Vidal-Michel JP, Bourrel Y, Emsallem J, Bonerandi JJ. [Surgical consideration of the moderately incontinent internal saphenous junctions using the "siphon effect" in varicose patients]. Phlebologie 1993;46:143-7. French.

25. Theivacumar NS, Darwood RJ, Gough MJ. Endovenous laser ablation (EVLA) of the anterior accessory great saphenous vein (AAGSV): abolition of sapheno-femoral reflux with preservation of the great saphenous vein. Eur J Vasc Endovasc Surg 2009;37:477-81.

26. Creton D. Diameter reduction of the proximal long saphenous vein after ablation of a distal incompetent tributary. Dermatol Surg 1999;25:394-7.

27. Labropoulos N, Tiongson J, Pryor L, Tassiopoulos AK, Kang SS, Ashraf Mansour M, et al. Definition of venous reflux in lower-extremity veins. J Vasc Surg 2003;38:793-8.

28. Cappelli M, Molino Lova R, Ermini S, Zamboni P. Hemodynamics of the sapheno-femoral junction. Patterns of reflux and their clinical implications. Int Angiol 2004;23:25-8.

29. Colignon A, Hébrant J. Superficial venous reflux: importance of the refluxing volume. XXXVIIIe Meeting of the European Society for Phlebectomy;2008 Apr 12;Brussels, Belgium.

30. Christopoulos D, Nicolaides AN, Szendro G. Venous reflux: quantification and correlation with the clinical severity of chronic venous disease. Br J Surg 1988;75:352-6.
31. Owens LV, Farber MA, Young ML, Carlin RE, Criado-Pallares E, Passman MA, et al. The value of air plethysmography in predicting clinical outcome after surgical treatment of chronic venous insufficiency. J Vasc Surg 2000;32:961-8.

32. Pittaluga $P$, Chastanet $S$, Locret $T$, Barbe R. Haemodynamics improvement assessed by air plethysmography after phlebectomy and saphenous preservation. 20th Annual meeting of the American College of Phlebology; 2006 Nov 10;Jacksonville, FL, USA.

33. Merchant RF, Pichot O; Closure Study Group. Long-term outcomes of endovenous radiofrequency obliteration of saphenous reflux as a treatment for superficial venous insufficiency. J Vasc Surg 2005;42:502-9; discussion 509.

34. Nicolini P; Closure Group. Treatment of primary varicose veins by endovenous obliteration with the VNUS closure system: results of a prospective multicentre study. Eur J Vasc Endovasc Surg 2005;29:433-9.

35. Kostas T, Ioannou CV, Touloupakis E, Daskalaki E, Giannoukas AD, Tsetis D, et al. Recurrent varicose veins after surgery: a new appraisal of a common and complex problem in vascular surgery. Eur J Vasc Endovasc Surg 2004;27:275-82.

36. Winterborn RJ, Foy C, Earnshaw JJ. Causes of varicose vein recurrence: late results of a randomized controlled trial of stripping the long saphenous vein. J Vasc Surg 2004;40:634-9.

37. Labropoulos N, Leon M, Nicolaides AN, Giannoukas AD, Volteas N, Chan P. Superficial venous insufficiency: correlation of anatomic extent of reflux with clinical symptoms and signs. J Vasc Surg 1994;20:953-8.

38. Perrin MR, Labropoulos N, Leon LR Jr. Presentation of the patient with recurrent varices after surgery (REVAS). J Vasc Surg 2006;43:327-34; discussion 334.

39. Min RJ, Zimmet SE, Isaacs MN, Forrestal MD. Endovenous laser treatment of the incompetent greater saphenous vein. J Vasc Interv Radiol 2001;12:1167-71.

40. Proebstle TM, Moehler T, Herdemann S. Reduced recanalization rates of the great saphenous vein after endovenous laser treatment with increased energy dosing: definition of a threshold for the endovenous fluence equivalent. J Vasc Surg 2006;44:834-9.

41. Pichot O, Kabnick LS, Creton D, Merchant RF, Schuller-Petroviae S, Chandler JG. Duplex ultrasound scan findings two years after great saphenous vein radiofrequency endovenous obliteration. J Vasc Surg 2004;39:189-95.

42. Lurie F. New investigations for venous valve insufficiency: perspective for early detection. Presented at: Ninth Annual Meeting of the European Venous Forum;2008 Jun 26-28;Bar- 
celona, Spain.

43. Porto LC, da Silveira PR, de Carvalho JJ, Panico MD. Connective tissue accumulation in the muscle layer in normal and varicose saphenous veins. Angiology 1995;46:243-9.

44. Gandhi RH, Irizarry E, Nackman GB, Halpern VJ, Mulcare RJ, Tilson MD. Analysis of the connective tissue matrix and proteolytic activity of primary varicose veins. J Vasc Surg 1993;18:814-20.

45. Lengyel I, Acsády G. Histomorphological and pathobiochemical changes of varicose veins. A possible explanation of the development of varicosis. Acta Morphol Hung 1990;38:259-67.
46. Abu-Own A, Scurr JH, Coleridge Smith PD. Saphenous vein reflux without incompetence at the saphenofemoral junction. Br J Surg 1994;81:1452-4.

47. Schanzer H, Skladany M. Varicose vein surgery with preservation of the saphenous vein: a comparison between high ligation-avulsion versus saphenofemoral banding valvuloplasty-avulsion. J Vasc Surg 1994;20:684-7.

48. de Roos KP, Nieman FH, Neumann HA. Ambulatory phlebectomy versus compression sclerotherapy: results of a randomized controlled trial. Dermatol Surg 2003;29:221-6. 